\title{
Hakikat ve Mecaz Arasında Bir Sufi'nin Portresi (Melayê Cizîrî), Mehmet Nesim DORU, i̇stanbul, Nûbihar Yayınları, (Birinci Baskı 2016), 139 S.
}

Wellah ji herdu ‘âleman min hüsne canan e xered Lew min ji husna dilberan her sun'ê Rahma e xered Vallahi, her iki dünyada da hüsn-ü canandır maksadım Dilberlerin güzelliğinde ilahi sanatı seyretmektir amacım

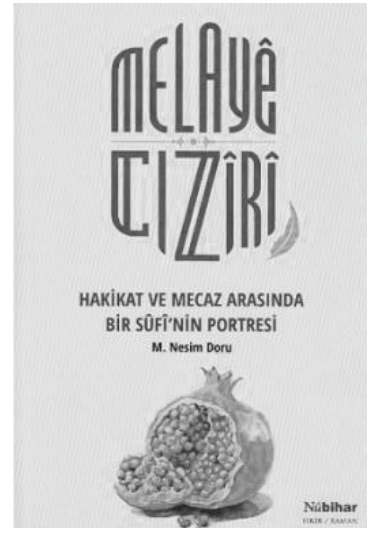

Düşünce dünyamıza edebiyattan felsefeye birçok konuyu ihtiva eden Divan eserini miras bırakan Melayê Cızîrî sadece bir şair değil, aynı zamanda İslam düşüncesinin birçok disiplinine vakıf bir sufi düşünürdür. Divan, içerdiği nazari konularla İslam düşünce tarihinde bu kapsamda ve vecizlikte yazılmış nadir eserlerden birisidir. Melayê Cızîrî Divan'ında, 17. yüzyılın genel karakterini yansıtarak tasavvuf düşüncesini merkeze alıp İslam felsefesinin diğer (Meşşâî, İşrâki) yönelimlerinin tümüne veciz ifadelerle yer vermiş ve hakikate ulaşmanın ancak mecaz ile mümkün olabileceğini her fırsatta vurgulamıştır.

Mehmet Nesim Doru bu kitabında, hakikat arayışının tecrübesini bütün basamaklarıyla divanında önümüze seren bir sufinin portresi ile karşımıza çıkmıştır. Eserde tasavvuf tecrübesi, Melayê Cızîrînnin şahsında hakikat-mecaz, nur, tecelli, marifet, insan ve nihayetinde aşk olarak takdim edilmektedir. Adeta saklı mistik bir hazine olan Melayê Cızîrî'nin Divan'ını, daha önce de Nubihar yayınlarından çıkan Melayê Cızîrî (Felsefi ve Tasavvufi Görüşleri) eseriyle akademi dünyasının istifadesine sunan yazar, bu kitabında ise yine bu saklı hazineyi hakikat-mecaz ilişkisi bağlamında felsefi analizler yaparak ele almakta ve araştırmacıların beğenisine sunmaktadır.

Kitabın kapağındaki yarılmış nar resmi aslında kitapta karşılaşacağımız sufi düşüncedeki vahdetu'l-vücûd felsefesinin adeta bir özetini yansıtmakta ve aslında işi hülasa etmektedir. Kitap, iki ana kısım ve sekiz alt başlıktan oluşmaktadır. Giriş 
kısmından hemen sonra Melayê Cizîrî’nin dil ve düşünce dünyası ele alınarak Mela'nın mistik düşüncesinin alt yapısı ortaya konulmuştur. İslam Felsefesi Ekolleri Işığında Melayê Cizîrî’nin görüşlerinin detaylarına yer verilen birinci ana bölümde; İbn Sina özelinde Melayê Cizîrînnin Meşşâî felsefeye olan yaklaşımı ve diğer iki alt bölümde ise İşrâki düşünceye ve tasavvuf felsefesine olan ilgisi divanından değişik beyitlerle analiz edilerek anlatılmıştır. Kitabın ana iskeletini oluşturan ikinci kısımda ise yazarın ön plana çıkarmaya çalıştığı Melayê Cızîrînin Tasavvuf felsefesi ışığındaki görüşleri detaylandırılmıştır. Hakikat ve mecaz, nur ve tecelli, marifet, insan ve aşk alt başlıklarında da adeta Mela'nın düşünsel bir portresi çizilmiştir.

Kitabın ön söz ve giriş kısmında gerek Melayê Cizîrî gerekse elimizdeki tek eseri Divan'ı hakkında yurt içinde ve yurt dışında yapılmış araştırmalardan söz eden yazar, hala Mela'nın gün yüzüne çıkarılmayı bekleyen yönlerinin olduğunu ve bu konuda yapılan çalışmaların yetersizliğini vurgulamaktadır (s.9). Asıl adı Molla Ahmed Ibn Molla Muhammed olup “Mela” mahlasıyla bilinen ve aslen Cizreli olup Cizre'nin Buhtî aşiretine mensup olan Melayê Cizîrî, doğum yılının tam olarak bilinmediğinin vurgulandığı kitapta, onun on yedinci yüzyılın ortalarına doğru vefat ettiği kanısına varılmaktadır (s.14). Yazar haklı olarak Kürtçeyle kaleme alınan Melayê Cizîrî'nin eserini, Farsça yazılan Hafız Şirazî, Mevlâna ve Molla Camî'nin, Arapça yazılan Ibn Fariz ve Türkçe yazılan Fuzuli'nin divanlarına benzetir (s.14). Kitapta Mela'nın medrese geleneğinden gelen bir mutasavvıf olduğu, felsefe, astronomi, fıkıh ve tarih ilimlerine olan vukufiyetinin yanında, tarikat ve medreseyi ya da akli ve kalbi ilimleri birleştirmesi gayreti, divandan değişik beyitlerle ön plana çıkarılmıştır. Her ne kadar Meşşâi felsefeye ilgisi gözden kaçırılamayan Mela'nın, akıl, kıyas ve burhandan daha çok keşf ve sezgi gibi sufi felsefenin bilgi kaynaklarını kabul ettiği her fırsatta ortaya konulmuştur. Divanın birçok tasavvufi sembol ve metaforla dolu olması bunun en büyük kanıtı olarak gösterilmiştir (s.15). Sıradan insanların idrak edemediği hakikatlere keşf ve sezgi ile muttali olan sufinin dilinin ancak "sembolik ve paradoksal" bir sanatsal dil olabileceği ve bunun Kürt edebiyatındaki en önemli örneğinin, Mela'nın divanı olduğu her fırsatta dile getirilmiştir. Mela'nın düşünsel portresinin çizilmeye çalışıldığı eserde, yaşadığı dönemin temel karakterine uygun olarak felsefe, tasavvuf ve kelam başta olmak üzere İslami ilimleri bir araya getirme başarısı elde ettiği ve onun hem molla hem şeyh hem sufi hem âşık hem de bilge olduğu böylelikle mümtaz bir yere sahip olduğu vurgulanmıştır (s.26)Kürt edebiyatı açısından bir şaheser olarak kabul edilen Melayê Cizîrînnin divanı, İslam düşüncesinin teorilerini, şiirin sınırlarını zorlayacak şekilde işlediği ve bu yönüyle edebiyattan mitolojiye, felsefeden astronomiye, tasavvuftan tarih ve coğrafyaya kadar birçok alan ile ilgili olarak o dönemin bir resmi gibi okunabileceğini anlatmaya çalışan yazar, Kürt dilinin şiirsel anlatım zenginliğinin de altını çizmiştir. Burada Melayê Cizîrînin otuz sene boyunca müderrislik yaptığı Medrasâ Sor’a (Kırmızı Medrese) vurgu yapılan kitapta, Kürt medreselerinin hem zahiri hem bâtıni ilimleri yani şeriatı ve tarikatı birleştiren yapısının, Mela'nın şahsında vücut bulduğu hususunu ortaya çıkardığı söylenebilir. Yazara göre Melayê Cizîrî’nin yaşadığı dönem İslam düşünce ekollerinin birer geleneğe dönüştüğü bir dönemdir. Bu dönemde "Ișrâkilik" ve "Felsefi tasavvuf” 
öne çıkmaktadır. Melayê Cizîrî’nin yaşadığı dönemde, bir tarafta Mir Damad ve Molla Sadra gibi filozofların şekillendirdiği İşrâkilik İran coğrafyasında, diğer tarafta ise İbn'ül-Arabi tarafından sistematik hale getirilen ve Şems-i Tebrîzî, Mevlana Celâleddin Rûmî ve Sadreddîn Konevî gibi sufi filozofların şekillendirdiği Anadolu coğrafyasında birer düşünce ekolüne dönüșmüşlerdir. Cizre'nin bu iki coğrafik bölgenin arasında kalması nedeniyle Mela'nın bu iki ekolun etkisinde kaldığı hususu bir başka dikkat çekilen durumdur (s.33). Bunun dışında Hallâcı Mansûr, ỉbn Sînâ ve İbn Seb'în gibi İslam felsefesi düşünürlerinden de etkilendiği kitapta geçen bir başka ayrıntıdır (s.33).Melayê Cizîrînnin İbn Sînâ ilgisi ve Meşşâî felsefeye olan eleştirel aklın hakikati bulmada yetersiz oluşu gibi yaklaşımının yanı sıra, "vâcib/Vacibu'l-Vücûd" ve "imkân" kavramlarını veciz ifadelerle kullanması divandan şu beytin alıntısı ile açıklanmaktadır:Ji sırra lâ mekân wâcib tenezzül kir di imkânê

Fe eyne'l ‘ilmu ve eyne'l-‘eyn we eyne’l-eynu iz la eyn

İmkân âlemine tecelli etti Vacbu'l-Vücud la-mekân sırrından

Nerede ilim, nerede zat, nerede mekân, 'nerede' diye bir şey yok (s.34).

Mela'nın divanında nur ve türevleri ile ilgili terimleri kullanması, keşf ve sezgiye yer vermesi İşrakîfelsefeye yakınlığını göstermekle beraber, akli yöntemler üzerine kuruduğu rasyonel bir sezgi anlayışıyla da Meşşâilliğe yaklaştığı yine kitapta dikkat çekilen Mela'ya ait diğer bir özelliktir (s.38-40). Melayê Cizîrî'nin kitapta çizilmeye çalışılan portresinin esas yönü ise felsefi tasavvufa olan ilgisi olarak gösterilmektedir. Yazara göre Divan baştan sona sufi düşüncenin temalarıyla doludur. Özellikle vahdetü'l-vücûd, kenz-i mahfi, hakikat-ı muhammediye, tecelli, hakikat-mecaz, kefş, marifet, zühd ve melamet bu temaların başlıcaları olarak sayılabilir (s.9). Kitapta Melayê Cizîrî’de Felsefi Tasavvuf alt başlığı altında öncelikle incelenen kavram íbn'ül-Arabi ve takipçilerinin tasavvufun temeli saydıkları vahdetü’l-vücûd kavramıdır. Ayrıca Mela, yaratılıș mertebelerini detaylandırırken sermediyyet, kıdemiyyet ve samediyyet gibi isimleri tercih etmektedir. Tıpkı selefi olan diğer sufi filozoflar gibi Mela da "la taayyün mertebesi" ile diğer mertebeleri sayarken, isim ve sıfatlarla tecelli eden varlığın daha sonra ruh ve misal âlemi ile tecelli ettiğini ve nihayet somut ve çoklu eşya şeklinde dış dünyaya zuhur ettiğini ifade eder. Yazar karşımıza Mela'nın bu konuda yani varlığın baştan sona bir birlik olduğu hususunda bir başka veciz ifadesini taşır: Her hey'et û her cismekî her ferd û new'û qısmeki

Rûh wî di destê ismekî mayî di qabzêw pençe da

Varlıkların her bir nevi, her bir ferdi, her bir kısım ve heyeti

Allah'ın güzel isimlerinden birinin idaresi ve hükmü altındadır (s.45-46).

Kitabın en çarpıcı bölümlerden birisi de "aşk" başlığı altında Melayê Cizîrî’nin düşüncelerinin aktarıldığı bölümdür. Çünkü yazara göre Mela, çağının 
sufi geleneğini hakkıyla temsil etmektedir. Aşk konusu da onun alametifarikası sayılabilir. Bu bağlamda 'aşk'ın biri ontolojik diğeri varoluşsal iki anlamı ișlenir. Ona göre aşk varlık âleminin kaynağı ve sebebidir. Tanrısal zatın kendisine âşık olması ile başlayan tecelli süreci, varlık denilen bütünü oluşturmuştur. Sufi gelenekteki bu hâkim anlayış Melayê Cizîrî'nin divanında veciz ifadelerle yer bulur:

\section{Husnê hub anî zuhûrê, işq e eslê 'âlemê \\ Eslê eşya da bzanî wan çi esl û madde bû \\ Güzellik sevgiyi zuhura getirdi, aşktır âlemin sebebi \\ Bil ki eşyanın aslında onlar var, unsurda ve maddede}

Mela'ya göre sufinin mecazı aşıp hakikate erişmesi marifet ilimlerini bilmesi ve fena makamına ulaşması ile olur. Aksi takdirde sadece mecazi aşka yoğunlaşmak ilahi sanatı ve güzelliği bütünüyle görmeye engeldir. Kitap, Melayê Cizîrînnin en çok bu yönünü ortaya çıkarmış ve bu konudaki beyitlerini analiz ile devam etmiştir. Mela düz yazılar yazmaktansa şiirin imkânını kullanmaktadır. Bu nedenle onun düşünce dünyasının kavramları Kürt medreselerindeki ilmî faaliyetleri ve dönemin ilim dünyasını derinden etkilemiştir. Nitekim yazara göre Mela'dan sonra Kürt medreselerinde gramerden sözlüklere tasavvuftan dinî eserlere kadar birçok çalışma manzum olarak yazılmıştır (s.50-51). Tanrı ve insan arasındaki ilișkiyi bir tür tevhid ilişkisi olarak gören tasavvuf felsefesi, Tanrı ve insan arasında bir ayırım yapılmasını kabul etmemektedir. Felsefe ve kelamın teşbih ve tenzih konularında ikisinden birini tercih ederek düştüğü çıkmaza, sufi filozoflar düşmeyip hem tenzihi hem teşbihi öncelemişlerdir. Kitap Melayê Cizîrî’nin de döneminin sufi filozoflarından biri olduğu ve İşrâki gelenekten de etkilendiğini ortaya koymaya çalışır. Bu nedenle kitabın ikinci bölümü Mela'nın tasavvuf felsefesi görüşlerini beş temel meselede ele alır. Bunlar: hakikat ve mecaz, nur, tecelli, marifet ve aşk'tır. Tasavvuf felsefesinin en önemli konusunun varlık olduğunu vurgulayan yazar, sufi düşüncenin mevcut somut varlık dünyasını, gerçek varlığa nispetle rüya, vehim ve hayalden ibaret gördüğünü söyler. Yani varlığın biri “hakikat” ve diğeri de "mecaz" görünümleri olduğu yoluyla bu problemi çözmeye çalışır. Vahdet'ül-vücûd, mutlak varlığın veya birliğin çeşitli açıım süreçlerinden geçerek insan zihnine çokluk olarak göründüğünü tazammun ettiğini ifade eden yazar, Melayê Cizîrî̀nin divanında:

Dı qıdem da ezelû 'eynê ebed her du yek in

Sermediyyet we dixwazit ne ezel bit ne ebed

Ferq e wahid ji ehed lê di meqamê semedî

Bi heqiqet ku yek in herdu çi wahid û çi ehed

Ezel ve ebed aynı şeydir kıdemiyette

Çünkü ezel ve ebed farkı yok sermediyette

Gerçi sözcüklerde farklıdır "vâhid" ile "ehad"

Lakin gerçekte yoktur farkları birleștirir onları samed" 
diyerek tüm fenomenler âlemini, mutlak varlığın bir görüntüsü ve tecellisinden ibaret gördüğünü yine kendine has veciz ifadelerle izah eder. Bunun yanında Mela, varlığın dikey boyutta yukarıdan aşağıya doğru nuru azalarak yokluğa ve karanlığa doğru giden bir tasavvurdan, yukarıdan aşağıya ve tekrar aşağıdan yukarıya çıkan bir döngü ile açıklar. Ve bu döngünün tam ortasında insan vardır. Ona göre insan hazreti, varlık âleminin tekrar yükselme sürecinin başladığı yerdir. Eşyanın tümü de tanrısal isim ve sıfatların aynasıdır (s.56-63).Yine marifet kavramının Melayê Cizîrî̀de önemli olduğu ortaya konulmuștur. Kitaba göre Mela, merkezi kalp ve sonucu zevk olan marifeti öne çıkarıp, merkezi akıl ve sonucu ilim olan rasyonel bilgilenme sürecini yadırgamıştır. Hakikate giden yol marifettir. Salik bu yolla fena mertebesine ulaşır. Burada da mecazdan hakikate geçer. Fena makamından fenomenler dünyasına tekrar dönen salik, bu makama çıkmadan önce gerçeklik olarak kabul ettiği mecazlar dünyasını çözer ardındaki hakikati görür. Sufi düşünce hakikatin anlatılamaz olduğunu savunduğu için mecaz ve sembolleri kullanmayı tercih eder. Bu özel tecrübeyi yaşayan sufinin bunu dilsel anlatımlara ortaya koyması zordur. Bu nedenle de mecaz ve semboller kullanılır. İşte kitapta anlatılan bir diğer husus Melayê Cizîrînnin divanının bu mecaz ve sembollerle dolu olduğu hususudur. Yazara göre bunların en önemlileri, ayna, harf-nokta, ve su-deniz mecazlarıdır (s.67-77).Mela'nın şiirlerinde içerik, üslup ve yöntem olarak Muhyiddîn íbnü’l-Arabî ekolünden çokça etkilendiğini görmek mümkündür. Okuyucu, Melayê Cizîrî’nin divanını kitapta yer alan felsefi izahlar ışı̆̆ında okuduğu zaman adeta, İbnü'l-Arabî'nin el-Futûhâtü'l-Mekkiyye ve Fusûsu'l-Hikem adlı eserlerinin veciz anlatımlarını Kürtçe dilinin şiirselliğinden yararlanılarak bir sanat eserini temaşa ettiği duygusuna kapılır. Her beytinde hâkim düşüncenin tasavvuf felsefesi olduğu âşikâr olan bu şaheserin akademinin istifadesine bu şekilde sunulması takdire şayandır. Mela'nın divanından, Tanrı'nın kendi zatına âşık olarak âlemi yaratması hususu ve dolayısıyla Tanrı'nın hem âşık, hem maşuk hem de aşkın kendisi olması anlayışı da kitapta öne çıkarılan bir başka konudur. Tanrı'nın âleme el-Vedûd sıfatı ile tecelli etmesi, aşkın altının bir kez daha çizildiği yerdir. Yine kitapta âlem mülkünün sultanının insan olduğu ve bütün tecellilerin mücessem halinin insan olduğu gerçeğinin Mela'nın beyitlerinde karşımıza çıktığı anlatılmaktadır. İnsan Tanrısal nurun tecelli ettiği en önemli varlıktır. Mela'ya göre insan sadece maddi bir varlık değildir. Kitapta Mela'nın, insan hava, su, toprak ve ateş unsurları dışında meleklerin ve ay üstü varlıkların sahip olduğu beşinci bir unsura sahip olduğu noktası da önem arz eder. Ona göre insan, kadim ve hadis, lâhût ve nâsût, aşkın ve içkin tüm varlığın hülasasıdır(s.78-94)Kitabın Mela ile ilgili ön plana çıkardığı en önemli husus ise müstakil bir başlıkta incelenen "aşk" mevzusudur. Aşkın tecrübi bir hal olması nedeniyle şiir dilinin aşk konusunu anlatmaya ne kadar uygun olduğu ve Mela'nın bundan istifadesi değişik beyitlerle anlatılmıştır. Çünkü yazara göre Mela'nın divanında hâkim tema așktır. Așk Mela'ya göre bir sırdır. Ancak tanımının yapılamaması hakkında konuşulmayacağı anlamına gelmez. Bu nedenle Mela divanda her fırsatta aşktan konuşmaya çalışmıştır. 
Tu j'Melayî her bipirs esrarê işqê hel dikit

Vê mu'ammayê çiz anin sed mela û müste’id

Mela'ya sor aşkın sırlarını ki, halletsin sana

Çözemez yoksa bu muammayı yüz molla ile müstaid

Aşk sırların sırrıdır Mela'ya göre bu nedenle kitapta bu özel bölümde; Bir sır olarak, varlığın kaynağı ve varoluşun sırrının aşk olduğu, sufi literatürden örneklerle Mela'nın divanındaki aşk beyitleri karşılaştırılarak ortaya konulmaya çalışılmıştır. Özellikle Mevlana'ya olan benzerliklerin altı çizilmiştir (s.100).Kitap büyük Kürt mutasavvıfı ve divan sahibi Melayê Cizîrî’nin bir portresini çizme hususunda gayet başarılı hazırlanmış, gereksiz detaylardan uzak bir şekilde bu aşk adamının hakikate ulaşmak için tercih ettiği şiir dilinin imkânlarını ortaya koymaya çalışmıştır. Akıcı üslubu ve aralara divandan serpiştirilmiş beyitlerle sıkıcı bir akademik dilden uzak durulmuştur.Kitabın eleştiriye açık yönü ise son okumasının iyi yapılmamış olmasıdır. Örneğin, muhtemelen toplu düzeltmeden kaynaklanan ve birçok sayfada karşılaştığımız "konusudur" olması gereken kelimenin sehven, "konusüdûr" (s, 16, 60, 75, 76) şeklinde yazılması, "sudur" olması gereken kelimenin "südûr” şeklinde yazılması, (s, 21), "konusunda” olması gereken kelimenin "konunda" şeklinde yazılması (s, 95) ve birkaç yerde devrik cümlenin kurulmuş olması, iyi bir son okuma yapılmadan yayına gönderildiğini göstermektedir.

Son olarak, Melayê Cizîrî’nin şahsında tasavvuf düşüncesinin çarpıcı yönlerinin altını çizilmeye çalışıldığı bu eserin, onu tanıma ve tanıtmanın gayreti ile hareket ederek, batı ve doğunun ortasında bir coğrafyada yaşamış olan bu sufi düşünürün düşünce olarak da bu iki dünyadan istifade etmiş olduğu hususu, düşünsel portresi çizilerek anlatılmış bir çalışma olduğu söylenebilir.

\section{Selim ÖNCÜ}

Mardin Artuklu Üniversitesi

Sosyal Bilimler Enstitüsü

Felsefe ABD Yüksek Lisans Öğrencisi selimoncu@artuklu.edu.tr 